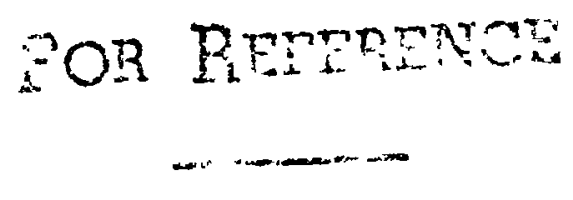

\title{
A Search for 183-GHz Emission From Water In Late-Type Stars
}

T.B.H. Kuiper, P.N. Swanson, D.F. Dickinson, E.IN. Rodriguez Kuiper and P. Zimmermann

LIBRARY COPY

$\therefore \because 1984$

LANGLEY RESEARCH CENIEK

LI3PARY NAST

H.i.JTh, VRESIMIA

\section{August 1984}

\section{N/SA}

National Aeronautics and Space Administratıon

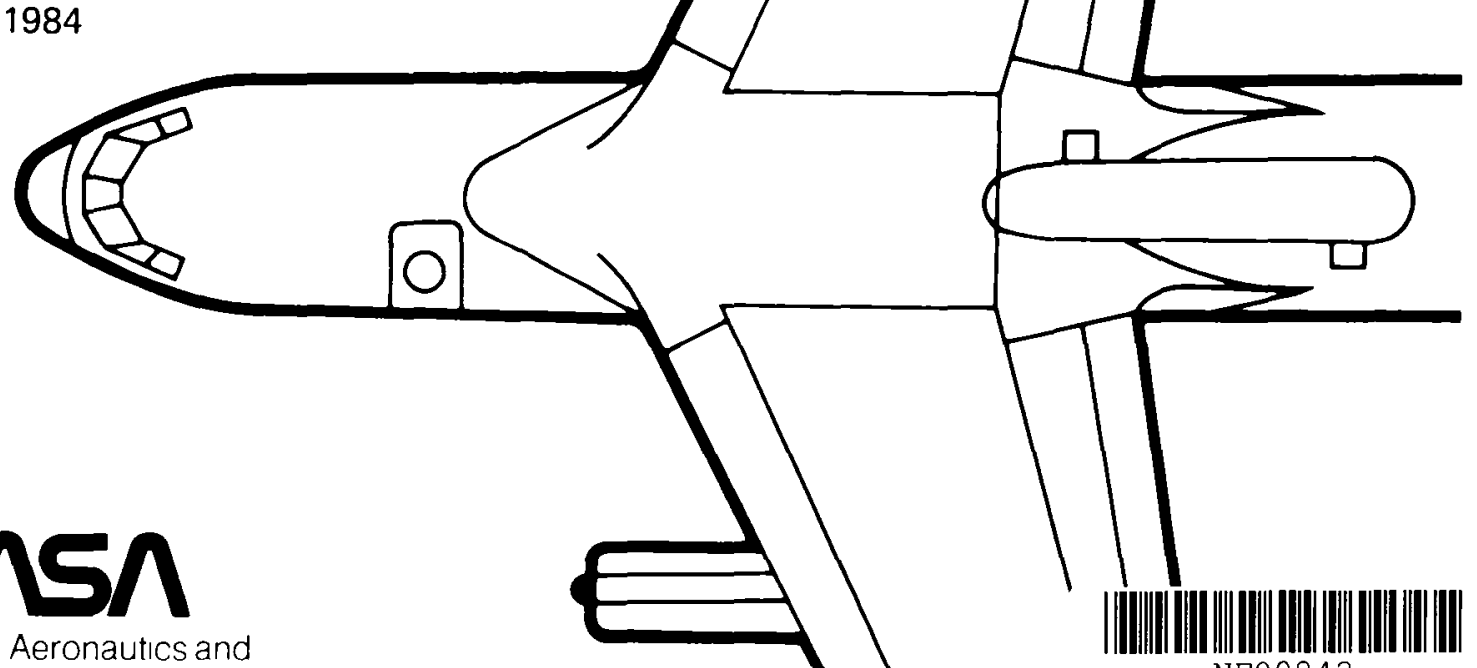

$\mathrm{NEO} 0842$ 


\section{A Search for 183-GHz Emission From Water In Late-Type Stars}

T B H Kuiper

$P$ N Swanson

D F Dickınson

E N Rodriquez Kuiper

P Zımmermann, Jet Propulsıon Laboratory, Calıforına Instıtute of Technology

\section{N/SA}

Natıonal Aeronautıcs and

Space Admınıstratıon 
A SEARCH FOR 183 GHz EMISSION FRON WATER

IN LATE-TYPE STARS

\author{
T. B. H. Kumper \\ P. N. Swanson \\ D. F. Dickınson 1 \\ E. N. Rodriguez Kuiper ${ }^{2}$ \\ P. Zimermann \\ Jet Propulsion Laboratory \\ California Institute of Technology
}

Received 1984 February 2; accepted 1984 May 18

$$
\text { to appear in }
$$

The Astrophysical Journal

Part I, November 1, 1984

1 While an employee of Ball Aerospace Systems DAvision working at JPL

2 While an NAS-NRC Senior Resident Research Associate 
A search was made for $183 \mathrm{GHz}$ line emission from water vapour in the drrection of twelve Mira and two semiregular variables. Upper limits to the emission are in the range of 2000 to $5000 \mathrm{Jy}$. It is estimated that thermal emission from the inner regions of late-type stellar envelopes wall be on the order of ten Jy. Maser emission, according to one model, would be an order of magnitude stronger. From the limited set sampled, the possibll:ty of very strong maser emission at $183 \mathrm{GHz}$ cannot yet be ruled out. 


\section{INTRODUCTION}

Molecular line spectra at centimeter and millimeter wavelengths have proven useful in determining the conditions in the envelopes surrounding giant and supergiant stars of late spectral type. They have shed 11ght on the gas-phase composition, isotopic abundances, radial structure of temperature and density, and mass loss rates (e.g., Zuckerman 1980a,b). While maser transitions are more difficul: to interpret than transitzons between thermally populated levels, their sensitivity to particular combinations of environmental parameters gives them the potential of being rather fine probes of specific regions around a star. Water vapour emission at $22 \mathrm{GHz}$ arises in the acceleration region of the envelope within a few stellar radii of the star $\left(\sim 10^{14} \mathrm{~cm}\right)$, where the temperature is $1000-2000 \mathrm{~K}$ (Vardya 1970; Goldreich 1980). Sio masers also occur in the inner region of the envelope. $1612 \mathrm{MHz}$ OH masers occur at $>1000$ stellar radii (>1016 $\mathrm{cm}$; e.g., Bowers, Johnston, and Spencer 1981), where the temperature is $\sim 100 \mathrm{~K}$ (Elitzur, Goldreich, and Scoville 1976).

Another potential maser probe of stellar envelopes is the $183 \mathrm{GHz}$ line of water. In modelling the excitation of water in circumstellar envelopes, Deguchi (1977) has predicted an inversion of the $183 \mathrm{GHz}$ transition. That this transition does indeed invert under suitable conditions is demonstrated by the intensity of the wide wings of this line seen toward Ori KL (Kuiper, Zuckerman, and Rodriguez Kuiper 1981), and the variability of the emission from this source (Kuiper et al 1984). However, the conditions in the region in Orion where this emission arises are believed to be quite different from the stellar conditions modelled by Deguchi. A credible a priori prediction of $183 \mathrm{GHz}$ emission in any actual region is probably out of the question because the physical parameters such regions are not sufficiently well known 
(Goldreich 1980). We were therefore motivated to make a search for possible $183 \mathrm{GHz}$ maser emission in the envelopes of late-type glants and supergiants. Because of the 11mzted amount of observing time available at our observing altitude, we chose a strategy of surveying a large number of stars for strong emission, spending between one half and one hour on each star. We selected the stars primarzly on the basis of $\mathrm{OH}$ and $22 \mathrm{GHz} \mathrm{H}_{2} \mathrm{O}$ maser emission. Eleven of the fourteen stars we observed have such maser emission (Kleinmann, Dickinson, and Sargent 1978). This criterion selects late M stars with [0] > [C] (Vardya 1970; Wyckoff and Clegg 1978), and therefore those with generally lower mass-loss rates (2uckerman 1980; Knapp et al 1982). A number of preferred candidates could not be observed because they were not visible above 35 deg elevation at night on our assigned flight dates, because they could not be included in an efficient flight plan, or because of equipment failure. The stars observed are listed in Table 1.

\section{OBSERVATIONS}

The observations were made in 1980 February and August with a cooled Schottky-diode receiver mounted on the $91-\mathrm{cm}$ telescope of the G. P. Kuiper Airborne Observatory. The equipment used and the details of the calibration are extensively described in Kuiper et 81 (1984). We present here only a summary and additional facts of particular relevance to the observations described in this paper.

The system temperature was $\sim 900 \mathrm{~K}$, double sideband. The aperture efficiency was 0.40 , giving a sensitivity of $10^{4} \mathrm{Jy} / \mathrm{K}$. Typically, an I.m.s. noise level of $0.1 \mathrm{~K}$ was achieved in half an hour. Pointing was done by tracking the star observed, or an adjacent star, in a co-aligned tracking telescope, and is estimated to be accurate to $\sim 10 \mathrm{arcsec}$, which is a 
negligible fraction of the 8 arcmin beamwidth.

Two spectrometers were used. A 36-channel filter bank has 1-MHz

channels covering the central $11 \mathrm{MHz}$, twelve 3-MHz channels covering the ranges from 4.5 to $22.5 \mathrm{MHz}$ above and below the receiver's center frequency, and ten 8-MHz filters covering the ranges from 12 to $52 \mathrm{MHz}$ relative to the center. (In addition, there were three broadband channels.) The other spectrometer was a digital FFT device, covering the central 10 MHz with 256 channels, for any narrow spectral features that might be detected.

The principal obstacle to achieving the theoretical sensitivity of the receiver for broad lines proved to be severe standing waves in the telescope. To minzmize these as much as possible, we observed by chopping the subreflector in azimuth, symmetrically about the optical axis of the telescope. The total throw of the telescope beam was two beamwidths. The optical axis of the telescope was positioned one beawwidth either left or right of the star being observed. The signal recerved from the direction of the star and that from the blank sky on the opposite positzon of the optical axis were subtracted synchronously in the spectrometers. In the difference spectra, the amplitude of the standing wave was $\sim 10 \mathrm{~K}$ in 1980 February. The dominant periodicity was $\sim 70 \mathrm{MHz}$, which corresponds to a reflection path of $7 \mathrm{~m}$, twice the distance between the receiver and the subreflector. In addition, the pattern often appears to be partially modulated by a second sinusoid with half-period of $\sim 100 \mathrm{MHz}$, which corresponds to the distance between the receiver and a bulkhead port in the telescope cavity through which the beam from the receiver must pass to reach the tertiary flat. While the standing wave pattern consisted mainly of a dual sinusoid, the pattern was not regular enough so that it could be entirely removed by fitting a function. However, the pattern was smooth 
enough that our sensitzvity to narrow ( 1 Maz) lines was not significantly degraded. In 1980 August, we reduced the dominant standing wave pattern to about half by gluing to the center of the subreflector a small dask of Eccosorb foam with a diameter equal to the subreflector's image on itself.

The results are presented in Table 1. The first, second, and third columns give the name, spectral type, and variability type of each star observed, taken from Becvar (1959), Gehrz and Woolf (1971), and Kukarkin (1969). The fourth column contains the LSR velocity at the center of the spectrometers. The effective velocity coverage, with a resolution of $3 \mathrm{MHz}$ (4.8 $\left.\mathrm{km} \mathrm{s}^{-1}\right)$, was $45 \mathrm{MHz}\left(73 \mathrm{~km} \mathrm{~s}^{-1}\right)$ centered on the LSR velocity to which the receiver was tuned. The upper limit to the $183 \mathrm{GHz}$ flux, given in the fifth column, refers to narrow spectral features $\left(\sim 1 \mathrm{~km} \mathrm{~s}^{-1}\right)$ which we consider the more likely to be detected (see Discussion). It corresponds to twice the theoretical r.m.s. noise level. From our flat spectra, such as that of V1057 Cyg in Figure 1b, we were able to verify that we dad obta:n a channel-to-channel noise level consistent with our system temperature. Because of the uncertainty in our baselines, we consider this also to be the detection limit for broad spectral features.

We feel that the 2-o upper limit also applies to narrow features in spectra having poor baselines. Figure la shows a spectrum of a her in which such a feature appears to be present. The feature also appeared in the high resolution digital spectrometer. We cannot be confident that this is a real signal because the observation of this source was hindered by mechanical and tracking problems with the telescope. The spectrum consists of only one left-right pair, of which both parts were terminated early due to loss of tracking. The spectrum has the shortest integration time and the most irregular baseline of all our observations. The amplitude of the feature 
Is only 2-3 $\sigma$, depending on where one chooses to draw the baseline. It does lllustrate, however, that narrow features could be recognized even in the presence of strong standing waves. No other narrow features as prominent as the one in the a Her spectrum were observed.

In the spectra with poor baselines, our ability to detect broad spectral features is reduced. Such spectra have been identified with a cross next to the flux upper limit in Table 1.

\section{DISC USSION}

In order to assess the significance of the results, we can estrmate the intensity of the signals that wight be expected.

We consider first possible thermal emission. The flux density from water in local thermodynamic equilibrium in a stellar envelope at a distance $D$, in a line which has a width of $\Delta V$, may be written as

$$
S=\frac{X_{H_{2} O} N_{e n v} f_{3(1,3) A h v}}{4 \pi D^{2}(v \Delta v / c)}
$$

where $\mathrm{X}_{\mathrm{H}_{2} \mathrm{O}}$ is the relative abundance of water; $\mathrm{N}_{\mathrm{env}}$ is the total number of gas molecules in the envelope, $=6 \times 10^{56}$ times the mass of the envelope in Ho; $E_{3}(1,3)$ is the number of molecules in the $3_{1,3}$ rotational state of water, and is given in Eq. 2 of Waters et al. (1980); A is the probability of spontaneous emission, $=3.6 \times 10^{-6} \mathrm{sec}^{-1}$; and $\mathrm{h}, \nu$, and $c$ have their usual meanings. The equation may be conveniently expressed as

$$
\left[\frac{\mathrm{s}}{\mathrm{Jy}}\right]=7.4 \times 10^{11} \mathrm{x}_{\mathrm{H}_{2} \mathrm{O}}\left[\frac{\mathrm{M}_{\mathrm{env}}}{\mathrm{M}_{\mathrm{O}}}\right]\left[\frac{\mathrm{D}}{\mathrm{kpc}}\right]^{-2}\left[\frac{\Delta \mathrm{v}}{\mathrm{km} \mathrm{s} \mathrm{s}^{-1}}\right] \mathrm{T}^{-1.5} \exp \left(-\frac{204}{\mathrm{~T}}\right)
$$

The masses of late-type stellar envelopes have been estimated in the range 
of a few tenths to a few solar masses. The abundance of water is predictec to be almost as $h=g h$ as $10^{-3}$ because all the available oxygen not bound =0 carbon is in the form of water (Goldreich and Scoville 1976). However, we could imagine it to be as low as $10^{-6}$ if interstellar cloud chemistry is typical (e.g., Prasad and Huntress 1980). Adopting an appropriate average temperature presents some difficulty since the temperature in such envelopes varies from $\sim 10^{3} \mathrm{~K}$ near the star to a few tens of $\mathrm{K}$, or less, near the outer part of the envelope. The radial dependence is probably steeper than Inverse square root in the inner envelope because of absorption by dust in the envelope. We will adopt a temperature of $100 \mathrm{~K}$ because the emissivity of the $183 \mathrm{GHz}$ line is not a strong function of temperature, until the temperature drops below $60 \mathrm{~K}$ (see Fig. 2 in Waters et al 1980). The flux density from $183 \mathrm{GHz}$ line emission can then be expressed as

$$
S(L T E, \max )=3200\left[\frac{M_{\text {env }}}{M_{O}}\right]\left[\frac{k p c}{D}\right]^{2}\left[\frac{X\left(\mathrm{H}_{2} \mathrm{O}\right)}{10^{-3}}\right]\left[\frac{30 \mathrm{~km} \mathrm{~s}}{\Delta v}\right] \mathrm{Jy} .
$$

Assuming the lifetime of the outflow to be $\sim 10^{4}$ y (Knapp et al 1982), we can estimate the mass of the envelope from the mass-loss rate, and write the equation as

$$
S(L T E, \max )=320\left[\frac{\mathrm{dM} / \mathrm{dt}}{10^{-5} \mathrm{M}_{\mathrm{O}} \mathrm{yr}^{-1}}\right]\left[\frac{\mathrm{kpc}}{\mathrm{D}}\right]^{2}\left[\frac{\mathrm{X}\left(\mathrm{H}_{2} \mathrm{O}\right)}{10^{-3}}\right]\left[\frac{30 \mathrm{~km} \mathrm{~s}}{\Delta \mathrm{V}}\right] \mathrm{Jy} .
$$

This level of thermal emission, however, cannot be expected when one considers the density requirement for collisional excitation. Collision rates have been calculated by Green (1980) to be in the range of $10^{-12}$ to $10^{-11} \mathrm{~cm}^{3} \mathrm{sec}^{-1}$ for the 313 and 220 levels over a wide range of temperatures. The probabilities of spontaneous emission via the most probable pathways are 
$0.13 \mathrm{sec}^{-1}$ and $0.27 \mathrm{sec}^{-1}$, respectively, for these levels. Thus, if the stellar envelopes were optically than in these transitions, densities on the order of $10^{10} \mathrm{~cm}^{-3}$ would be required for collisional excitation to maintain the level populations against spontaneous decay. The density requirement is reduced if the emitted photons are reabsorbed by the envelope, since only photons which escape from the envelope cause a net de-excitation. This trapping cannot be very significant, however, since the expansion of the envelope causes most potentially absorbing molecules to be Doppler shifted away from the rest velocity in the frame of the emitting molecules. The radial density dependence of a uniform mass-loss may be expressed as

$$
n\left(\mathrm{H}_{2}\right)=1.5 \times 10^{9}\left[\frac{\mathrm{dM} / \mathrm{dt}}{10-5 \mathrm{M}_{\mathrm{yr}} \mathrm{yr}^{-1}}\right]\left[\frac{10^{14} \mathrm{~cm}}{\mathrm{r}}\right]^{2} \mathrm{~cm}^{-3}
$$

Thus, we see that collisional excitation can be expected to occur only within a few stellar radii (a few times $10^{14} \mathrm{~cm}$ ) of the surface for a mass-loss of $10^{-5} \mathrm{M}_{\mathrm{O}} \mathrm{yr}^{-1}$. Since, in a uniform outflow, the mass fraction interior to a given radius depends linearly on the radius, and since envelopes may extend to a few $\times 10^{16} \mathrm{~cm}$, we can only expect the few inner percent, or less, of the envelope to emit thermal $183 \mathrm{GHz}$ emission. The intensity of the line from the region is also reduced by the temperature dependent factor (see Eq. lb) because the inner core of the envelope has a temperature of $\sim 1000 \mathrm{~K}$. In the sixth colum of Table 1 , we have listed the distances of the stars, taken from Bowers, Johnston and Spencer (1983), Humphreys (1975), Knapp et al (1982), Morris and Jura (1983), and Wilson et al (1972). In the seventh column we have tabulated estimates of the mass-loss rate, taken from Bowers, Johnston and Spencer (1981), Gehrz and Woolf (1971), Knapp et al (1982), and Morris and Jura (1983). From these 
we have calculated, and tabulated in the elghth column, the factor $(d M / d t) D^{-2}$ in convenient units to facilitate comparison of the measured flux ligits with Equation 2b. To allow for the expected line width in Eq. $2 b$, we have also tabulated, in the ninth column, the outflow velocity, taken from Bowers, Johnston and Spencer (1981), and Knapp et al (1982). It is clear that the present observations are about three orders of magnitude too insensitive to detect thermal $183 \mathrm{GHz}$ water emission from these stellar envelopes.

Deguch I (1977) has modelled the excitation of water in the 2 nner envelope of a prototypical mass-loss star, in the range between one and two stellar radii (assumed to be $6 \times 10^{13} \mathrm{~cm}$ ). The velocity was assumed to be proportional to the distance from the surface of the star, the temperature dependence inverse square-root, and the mass-loss rate to be $10^{-5} \mathrm{M}_{\mathrm{sr}} \mathrm{yr}^{-1}$. He computed a $183 \mathrm{GHz}$ maser power of $1.3 \times 10^{43}$ photons $\mathrm{s}^{-1}$. Scaling his result to the mass-loss rate, $2 t$ corresponds to a flux at the earth of

$$
S_{183}=23\left[\frac{d M / d t}{10^{-5} M^{y r^{-1}}}\right]\left[\frac{\mathrm{kpc}}{D}\right]^{2}\left[\frac{\mathrm{km} \mathrm{s^{-1 }}}{\Delta V}\right] \mathrm{Jy} \cdot
$$

In Deguchi's velocity model, the amplification occurs in the acceleration region so that velocity coherence occurs only where the flow is perpendicular to the line-of-sight. Thus, the power may be expected to be confined to a thermal linewidth of $1 \mathrm{Mz}\left(=1.6 \mathrm{~km} \mathrm{~s}^{-1}\right.$ at $\left.1000 \mathrm{~K}\right)$ centered at the LSR velocity of the star. For a star at $0.2 \mathrm{kpc}$ with a mass-loss rate of $10^{-5}$ ib $\mathrm{yr}^{-1}$, the expected flux would be $360 \mathrm{Jy}$. Thus, the flux from Deguchl's model star at $200 \mathrm{pc}$ distance would lie about an order of magnitude below our detection level. Scaling from Deguchi's model, the stars observed should have emission about two orders of magnitude weaker than our detection level. 
The possibility that some stars may have intense maser emission well in excess of Deguchi's model, and potentially detectable by us, cannot be ruled out on the basis of our limlted survey which sampled only $13 \%$ of the known $22 \mathrm{GHz}$ water maser stars (Kleinmann, Dickınson, and Sargent 1978 ). Prospects for future searches should be quite good. With current technology, a Scottky-diode system with $400 \mathrm{~K}$ SSB system temperature is possible at $183 \mathrm{GHz}$. An SIS recezver might achieve half that, giving an order of magnitude better sensitzvity than the search reported here. Careful attention will need to be pald to reducing standing waves in the telescope system. Path-length modulator (e.g., a reciprocating mirror; Gustincic 1977) has been found to be effective in cancelling the effects of reflected radiation (Payne, 1983). Another order of magnitude improvement in sensitzvity can be achieved by using a 3-m balloon-borne telescope (Hoffmann, Fazio, and Harper 1983; Melchiorri 1983). A combination of these two advances will permit us to detect or put useful limits on $183 \mathrm{GHz}$ maser emission from late-type stars. Eventually, large orbiting telescopes such as FIRST (01thof 1983) and LDR (Swanson et al 1983) should permit the detection of thermal $183 \mathrm{GHz}$ line emission from water in stellar envelopes.

We express our gratitude to P. Batelaan and W. Ricketts for the engineering support which made this work possible, to M. Klein for assistance with the February observations, and to the staff of the G. P. Kuiper Airborne Observatory for their unstinting technical and observational support. The research described in this paper was performed at the Jet Propulsion Laboratory, California Institute of Technology, under contract with the National Aeronautics and Space Administration. 


\section{REFERENCES}

Becvar, A. 1959, Atlas CoelI II (Prague: Czech. Acad.)

Bowers, P. F., Johnston, K. J., and Spencer, J. H. 1981, Nature, 291, 382.

Deguch:, S. 1977, P.Astr. Soc. Jap., 29, 669.

Elitzur, M., Goldreich, P., and Scoville, N. 1976, Ap. J., 205, 384.

Fawley, H. M. 1977, Ap. J., 218, 181.

Gehrz, R. D., and Woolf, N. J. 1971, Ap. J., 165, 285.

Goldreich, P. 1980, in IAU Symposium 87, Interstellar Molecules (B. H. Andrew, ed.), Dordrecht, Reidel, p. 551.

Goldreich, P., and Scoville, N. Z. 1976, Ap. J., 205, 144.

Green, S. 1980, Ap. J. Suppl. 42, 103.

Gustincic, J. J. 1977, in IEEE MTT-S Int 1. Microwave Symp. Digest (E. R. Silverstein, ed.) Piscataway, N. J., IEEE, p. 99.

Hoffmann, W. F., Fazio, G. G., and Harper, D. A. 1983, Proc. SPIE, 444, in press.

Humphrey, R. M. 1975, Publ. A. S. P., 87, 433.

Hyland, A. R., Becklin, E. E., Frogel, J. A., and Neugebauer, G. 1972, Astr. and Ap., 16, 204

Johnson, H. L. 1968, Ap. J. (Lett.), 154, L125.

Kleinmann, S. G., Dickinson, D. F., and Sargent, D. G. 1978, A. J., 83, 1206. Knapp, G. R., Phililps, T. G., Leighton, R. B., Lo, K. Y., Wannier, P. G., Wootten, H. A., and Huggins, P. J. 1982, Ap. J. 252, 616.

Kuiper, T. B. H., Zuckerman, B., and Rodriguez Kuiper, E. N. 1981, Ap. J., 251,88

Kuiper, T. B. H., Rodriguez Kuiper, E. N., Swanson, P. N., Dickinson, D. F., Klein, M. J., and Zimmermann, P. 1984, Ap. J., 283, in press. Kukarkin, B. V., Kholopov, P. N., Efremov, Yu. N., Perova, N. B., Federovich, 
V. P., and Frolov, M. S. 1969, General Caralog of Variable Stars (3d ed.;

Moscow; Astronomical Council of the Academy of Sciences of the USSR).

Melchiorr:, F. 1983, Intl. Halley Watch Newsletter No. 3 (S. J. Edberg, ed.),

Pasadena, JPI, p. 2 .

Morrıs, M. and Jura, M. 1983, Ap. J., 267, 179.

01thof, H. 1983, Far Infrared and Submillimeter Space Telescope Assessment

Study, ESA $\operatorname{SCI}(83) 1$.

Payne, J. 1983, private communication.

Prasad, S. S., and Huntress, W. T., Jr. 1980, Ap. J. Supp1., 43, 1.

Swanson, P. N., Gulkis, G., Kuiper, T. B. H., and Kiya, M. 1983, Optical

Engineering, 22, 725 .

Vardya, M. S. 1970, Ann. Rev. Astr. AP., 8, 87.

Waters, J. W., Gustincic, J. J., Kakar, R. K., Kuiper, T. B. H., Roscoe,

H. K., Swanson, P. N., Rodriguez Kuiper, E. N., Kerr, A. R., and

Thaddeus, P. 1980, Ap. J., 235, 57.

Wilson, W. J., Schwartz, P. R., Neugebauer, G., Harvey, P. M., and

Becklin, E. E. 1972, Ap. J., 177, 523.

Wyckoff, S., and Clegg, R. E. S. 1978, M. N. R. A. S., 184. 127.

Zuckerman, B. 1980a, in IAU Symposium 87, Interstellar Molecules

(B. H. Andrew, ed.), Dordrecht, Reidel, p. 479.

Zuckerman, B. 1980b, Ann. Rev. Astr. Astroph., 18, 263. 


\section{ADDRESSES OF THE AUTHORS}

D. F. Dickinson - Lockheed Palo Alto Research Laboratory 3251 Hanover Street

Palo Alto, CA 94304

T. B. H. Kuiper, P. N. Swanson, P. Zzmmermann

Jet Propulsion Laboratory

California Institute of Technology

4800 Oak Grove Drive

Pasadena, CA 91109

E. N. Rodriguez Kuiper - Bennett Medical Equipment

12655 Beatrice Street

Los Angeles, CA 90066 
Table 1. Results of Search for 183 Gliz LIne Emission

\begin{tabular}{|c|c|c|c|c|c|c|c|c|c|}
\hline Star & $\begin{array}{l}\text { Spectral } \\
\text { Type }\end{array}$ & $\begin{array}{l}\text { Var. } \\
\text { Type }\end{array}$ & $\begin{array}{l}\text { Recelver } \\
\text { Central } \\
\text { v }_{1 \mathrm{gr}}\end{array}$ & $\begin{array}{c}\max \\
\mathrm{S}\end{array}$ & D & $d M / d t$ & $(d M / d t) / D^{2}$ & Vo & Ref $s$ \\
\hline$+\infty$ & $-\infty$ & 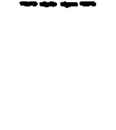 & $\left(\mathrm{km} \mathrm{s}^{-1}\right)$ & (Jy) & (kpc) & $\left(y^{y r^{-1}}\right)$ & $\begin{array}{c}\left(\mathrm{kpc}^{2}\right) /\left(10^{-5}\right. \\
\left.\mathrm{M}^{\mathrm{yr}} \mathrm{yr}^{-1}\right)\end{array}$ & $\left(\mathrm{km} \mathrm{s}^{-1}\right)$ & - \\
\hline $\begin{array}{l}\text { R Aql } \\
\text { RR Aq1 } \\
\text { R Cas }\end{array}$ & $\begin{array}{l}M 5 e-M 8 e \\
M 6 e-M 7 e \\
M 7 e\end{array}$ & $\begin{array}{l}M \\
M \\
M\end{array}$ & $\begin{array}{l}50 \\
31.5 \\
20\end{array}$ & $\begin{array}{l}2000 \\
2400 \\
1300\end{array}$ & $\begin{array}{l}0.3 \\
0.4 \\
0.2\end{array}$ & $\begin{array}{r}8 \times 10^{-7} \\
4 \times 10^{-7} \\
6.6 \times 10^{-7}\end{array}$ & $\begin{array}{l}0.89 \\
0.25 \\
1.65\end{array}$ & 11 & $\begin{array}{l}4 \\
2,6 \\
8,11\end{array}$ \\
\hline $\begin{array}{l}\text { U CVn } \\
\text { S CrB } \\
\text { NML Cyg }\end{array}$ & $\begin{array}{l}\text { M7e } \\
\text { M6e-M8e } \\
M 7 I\end{array}$ & $\begin{array}{l}M \\
M\end{array}$ & $\begin{array}{r}21 \\
1.5 \\
0.5\end{array}$ & $\begin{array}{l}3300^{a} \\
3300^{a} \\
2000^{a}\end{array}$ & $\begin{array}{l}0.4 \\
2.0\end{array}$ & $\begin{array}{r}4 \times 10^{-6} \\
6.4 \times 10^{-5}\end{array}$ & $\begin{array}{l}2.5 \\
1.6\end{array}$ & 23 & $\begin{array}{l}4,9,11 \\
2,7,10\end{array}$ \\
\hline $\begin{array}{l}\text { v1057 Cyg } \\
\text { a Her } \\
\text { U Her }\end{array}$ & $\begin{array}{l}\text { M5II } \\
\text { M6.5e-M8e }\end{array}$ & $\begin{array}{l}\text { SRc } \\
\text { M }\end{array}$ & $\begin{array}{r}4 \\
0 \\
-14\end{array}$ & $\begin{array}{l}2000 \\
5000^{a} \\
4000^{a}\end{array}$ & 0.3 & $\begin{array}{r}9 \times 10^{-8} \\
2.6 \times 10^{-6}\end{array}$ & 2.89 & & $\begin{array}{l}4 \\
4,11\end{array}$ \\
\hline $\begin{array}{ll}R & \text { Leo } \\
R & \text { LMI } \\
R & \text { Lyn }\end{array}$ & $\begin{array}{l}M 6.5 e-M 9 e \\
M 7 e \\
\text { S3e }\end{array}$ & $\begin{array}{l}M \\
M \\
M\end{array}$ & $\begin{array}{l}0 \\
1.5 \\
2\end{array}$ & $\begin{array}{l}2700^{a} \\
2700 \\
4000^{a}\end{array}$ & $\begin{array}{l}0.3 \\
0.4\end{array}$ & $\begin{array}{r}8.5 \times 10^{-7} \\
10^{-6}\end{array}$ & $\begin{array}{l}0.94 \\
0.63\end{array}$ & $\begin{array}{l}7 \\
6\end{array}$ & $\begin{array}{l}8,9 \\
8 \\
1\end{array}$ \\
\hline $\begin{array}{l}\text { R Peg } \\
\text { VX Sgr }\end{array}$ & $\begin{array}{l}\text { M7e } \\
\text { M41e-M9a }\end{array}$ & $\begin{array}{l}\text { M } \\
\text { SRb }\end{array}$ & $\begin{array}{r}26 \\
0\end{array}$ & $\begin{array}{l}2000 \\
3000^{a}\end{array}$ & 1.5 & & & & $\begin{array}{l}1 \\
3,5,9\end{array}$ \\
\hline
\end{tabular}

a Sensitivity 1 imited by standing waves.

\section{References}

1) Becvar 1959

2) Bowers, Johnston, and Spencer 1981

3) Fawley 1977

4) Gehrz and Woolf 1971

5) Humphreys 1975

6) Hyland et al 1972
7) Johnson 1968
8) Knapp et a1 1982
9) Kukarkin et al 1969
10) Morris and Jura 1983
11) Wilson et al 1972 


\section{FIGURE CAPTIONS}

Figure 1. (a) The spectrum observed in the direction of a her in the 183 $\mathrm{GHz}$ line of water vapour. The central channels are $1 \mathrm{MHz}$ wide; those adjacent, $3 \mathrm{MHz}$; the outer channels, $8 \mathrm{MHz}$. The full length of the error bar on the left corresponds to twice the r.m.s. noise level for the $1 \mathrm{MHz}$ channels as calculated from the measured system temperature. (b) As above for 1057 Cyg. 


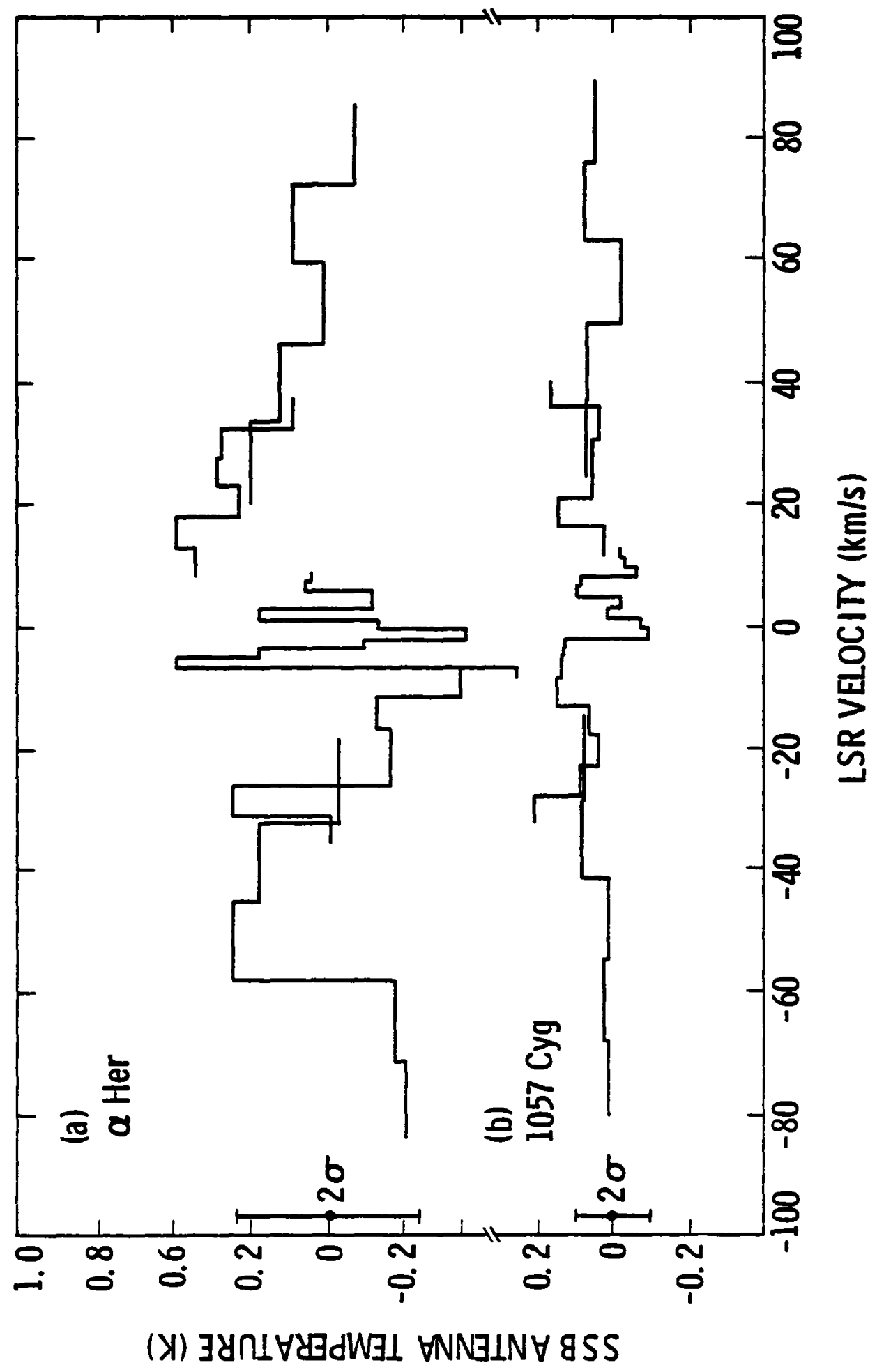

Fig. 1 


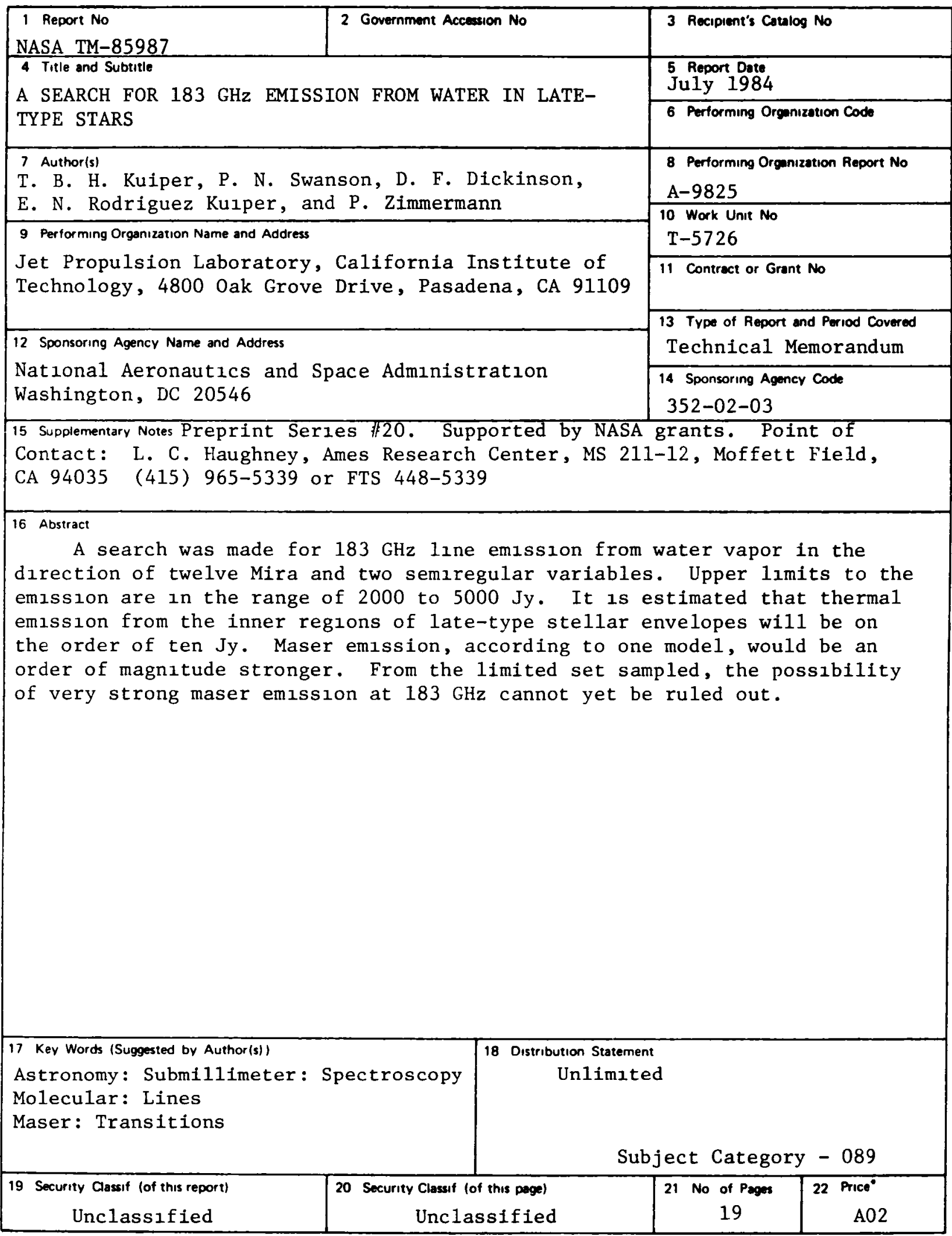

- For sale by the National Tochnical Information Service, Springfield, Virginia 22161 
End of Document 